\title{
Forensic patients in state psychiatric hospitals: 1999-2016
}

\author{
Amanda Wik, ${ }^{1 *}$ (1) Vera Hollen, ${ }^{2}$ and William H. Fisher ${ }^{3}$
}

\footnotetext{
${ }^{1}$ Research Associate, National Association of State Mental Health Program Directors Research Institute, Falls Church, Virginia, USA

${ }^{2}$ Senior Director of Research and Consulting, National Association of State Mental Health Program Directors Research Institute, Falls Church, Virginia, USA

${ }^{3}$ Senior Consultant, National Association of State Mental Health Program Directors Research Institute, and Adjunct Professor of Psychiatry and Community Health, University of Massachusetts Medical School, Worcester, Massachusetts, USA.
}

Introduction. In recent years mental health officials have reported a rise in the number of forensic patients present within their state psychiatric hospitals and the adverse impacts that these trends had on their hospitals. To date there have been no large-scale national studies conducted to determine if these trends are specific only to a few states or representative of a more global trend. The purpose of this study was to investigate these reported trends and their national prevalence.

Methods. The forensic directors of each state behavioral health agency (including the District of Columbia) were sent an Excel spreadsheet that had two components: a questionnaire and data tables with information collected between 1996 and 2014 from the State Profiling System maintained by the National Association of State Mental Health Program Directors Research Institute. They were asked to verify and update these data and respond to the questionnaire.

Results. Responses showed a $76 \%$ increase nationally in the number of forensic patients in state psychiatric hospitals between 1999 and 2014. The largest increase was for individuals who were court-committed after being found incompetent to stand trial and in need of inpatient restoration services.

Discussion. The data reviewed here indicate that increases in forensic referrals to state psychiatric hospitals, while not uniform across all states, are nonetheless substantial.

Conclusion. More research is needed to determine whether this multi-state trend is merely a coincidence of differing local factors occurring in many states, or a product of larger systemic factors affecting mental health agencies and the courts.

Received 16 November 2018; Accepted 16 April 2019; First published online 21 June 2019

Key words: Forensic patients, state psychiatric hospitals, incompetent to stand trial, pre-trial evaluations, inpatient.

This work was developed under Task 2.2 of NASMHPD's Technical Assistance Coalition contract/task order, HHSS283201200021I/ HHS28342003T, and funded by the Center for Mental Health Services/ SAMHSA of the Department of Health and Human Services through the NASMHPD. The authors gratefully acknowledge the expertise and technical review provided by the following national experts on forensic mental health services: Debra A. Pinals, M.D., W. Lawrence Fitch, J.D., and Katherine Warburton, D.O. Without their guidance, a study of this magnitude could not have been completed. We also extend our appreciation to the State Forensic Directors and other staff collaborators who spent many hours compiling and reviewing data for this study. The authors assume all responsibility for the scientific content of the paper.

*Address correspondence to: Amanda Wik, 3141 Fairview Park Drive Suite 650, Falls Church, VA, 22041, USA. (Email: Amanda.wik@nriinc.org).

\section{Introduction}

Recently, mental health officials have expressed concern regarding population shifts occurring in public psychiatric hospitals. Specifically, they have seen an increase in the number of "forensically involved" patients in these facilities. This trend is seen, in part, as an increase in the number of persons who have been brought to court on a criminal charge and subsequently court-ordered to receive inpatient services at state psychiatric hospitals. ${ }^{1-5}$ These "forensic patients" are referred to the state psychiatric hospitals to be evaluated (e.g., to determine their mental status at the time of the crime and their ability to comprehend court proceedings and/or assist their attorney with their case because of an apparent mental illness) or to 
be restored (e.g., to receive treatment services and/or educational interventions aimed at helping defendants regain their ability to understand the court process) prior to adjudication. ${ }^{1-8}$ Forensic patients can also consist of patients who have been court-ordered to receive inpatient services after a verdict has been reached on their case (e.g., individuals found to be not guilty but mentally ill, inmates who were transferred from a correctional facility for inpatient services, or individuals involved in the criminal justice system who were involuntarily civilly committed ${ }^{i}$ to a state psychiatric hospital for continued treatment). ${ }^{2,7-9}$ As can be seen, there are a variety of different types of forensic patients. This descriptive presentation is based on the major findings from a national study. ${ }^{i i}$ For the purposes of this study, this paper focuses solely on: (1) the overall forensic population, (2) patients who had been courtordered to receive pre-trial evaluations at a state psychiatric hospital, and (3) defendants who were found incompetent to stand trial (IST) and court-ordered to receive competency restoration services at a state psychiatric hospital. The term "forensic patients" is used in this paper to refer to all persons found "not guilty by reason of insanity," persons found "guilty but mentally ill," individuals transferred from correctional facilities seeking treatment services that are not available in the correctional setting, and, in some states, individuals involved in the criminal justice system who have been civilly committed to a state psychiatric hospital.

A large portion of forensic patients receiving services at state psychiatric hospitals consist of defendants who have been deemed IST ${ }^{\text {iii }}$ and court-ordered to receive competency restoration services. ${ }^{2,3,7,10}$ These services typically involve treatment and/or educational interventions aimed at helping defendants regain their ability to understand the court process and/or assist their attorneys in their defense. ${ }^{2,6}$ The apparent growth of this forensic population, in particular, has sparked the concerns of state officials. Many state officials have queried the National Association of State Mental Health Program Directors Research Institute (NRI) as to whether the rising forensic population in state psychiatric hospitals in their state, particularly IST patients, is a phenomenon that is unique to their state, or if this is a national trend.

Despite the growing concern centered around this trend, there are few national studies that have examined this "forensification" ${ }^{\text {"iv }}$ of state hospitals. ${ }^{7}$ This is indeed a valid concern. Forensic patients differ from civil patients ${ }^{\mathrm{v}}$ and patients who are involuntarily civilly committed. ${ }^{2,7-9}$ In

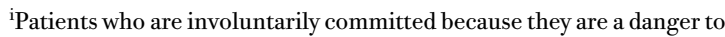
themselves or others but are not involved in the criminal justice system.

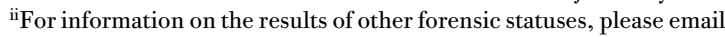
the author, or view the full report at: https://www.nri-inc.org/media/ 1318/tac-paper-9-forensic-patients-in-state-hospitals-final-09-05-2017. pdf.

iii In some states the term "incompetent to proceed" is used to refer to these patients.

${ }^{\mathrm{iv}}$ A term used to refer to the proportional increase in forensic patients present within state psychiatric hospitals. cases where a patient is being civilly admitted to a hospital, the hospital has the authority to determine who is to be admitted or discharged. Conversely, the admission and discharge of forensic patients is primarily controlled by the courts. Very few state psychiatric hospitals have the authority to discharge patients who have been court-ordered to receive inpatient services. ${ }^{2}$ Even though the admission and discharge process for forensic patients diverges from that of civil patients, the funding for these hospitalizations and their effect on bed supply are the concerns of the mental health system. ${ }^{9}$

Data from a national study are needed for policymakers to be able to address whether or not: the perceived "forensification" process is "real" and the rise in forensic patients is not a result of a declining civil population (e.g., the trend among forensic patients has remained steady, but the decline in civil patients has made it to appear as if the forensic population is growing).

Due to a lack of information on the scope of the issue and the potential factors that may be contributing to this apparent shift, this national study was developed to examine these factors. In doing so we address three questions regarding the perceived increase in the number of forensic patients: (1) Has there been an increase in the rate of state hospital admissions and census for all forensic statuses? (2) Are forensic patients becoming an increasing proportion of these hospitals' census? (3) Has the absolute number of patients receiving pre-trial evaluations and the number of IST patients who have been court-ordered to receive competency restoration services in state psychiatric hospitals services increased?

\section{Methodology}

\section{State-level data on forensic patients}

The NRI has worked with the Substance Abuse and Mental Health Services Administration's (SAMHSA) since 1996 to maintain the State Profiling System (SPS). The SPS collects and maintains qualitative and quantitative data on public behavioral health services, including all state psychiatric hospitals. For the purposes of this report, the NRI used the data collected by the SPS, which captured the number of forensic patients present within state psychiatric hospitals in each state and the amount that these hospitals were spending on those patients.

This study draws on state-level aggregate information from the SPS on the number of forensic patients present within all state psychiatric hospitals on a given "census day." ${ }^{\text {vi }}$ To assess the trends on forensic utilization, data

vThis term refers to patients who are not involved in the criminal justice system and are being treated at a state psychiatric hospital.

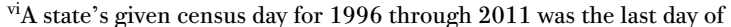
its fiscal year. In 2014 SAMHSA modified the data collection period, changing census day to the first day of the fiscal year. Since the data used for this study are based on SAMHSA's SPS, the given census day used for this study was changed. 
were collected from each state for the years 1996, 1999 , 2002, 2004, 2005, 2006, 2009, 2011, and 2014. Data were also obtained from the SPS regarding the state behavioral health agency's inpatient budget spending on forensic patients versus civil patients for each fiscal year from 2004 to 2015 .

\section{Data collection from states}

In addition to the data obtained from the SPS, we also queried state forensic directors. A series of Excel tables was sent to these officials as data collection instruments. The first table collected information for 2016. For each forensic status as well as for the total adult forensic population, the forensic directors were asked to indicate: the number of forensic patients present on the first census day of the state's 2016 fiscal year (FY), ${ }^{\text {vii }}$ the number of forensic patients admitted to the state psychiatric hospitals in FY 2016, ${ }^{\text {viii }}$ the average and median length of stay for forensic patients in FY 2016. A second table contained data on each forensic status from 1996 to 2014. Finally, a third table contained information collected between 2004 and 2015 on the number of patient-days and state psychiatric hospital budget spending on forensic and civil patients. Each forensic director was asked to review the information to verify its accuracy. If inconsistencies were found, the states were allowed to submit updated information.

To gain a better understanding of the challenges faced by each state and the perspectives of each state's forensic director on changes occurring among the forensic population, a questionnaire including 36 items taken from the National Association of State Mental Health Program Directors (NASMHPD) 2014 forensic mental health services report ${ }^{2}$ was sent (along with the tables described above) to the forensic director within each state and the District of Columbia. The questions were intended to collect information on: the percentage of competency-to-stand-trial (CST) evaluations that were being conducted on an outpatient basis, the percentage of patients who were receiving competency restoration services on an outpatient basis, whether or not there was a limit on how long defendants could be committed to the state psychiatric hospitals for competency restoration services, if the state maintains a waitlist for different types of forensic admissions, the length of time that defendants typically are on the waitlist (if applicable), and whether the state psychiatric hospital has ever been threatened with or held in contempt for not admitting IST defendants court-ordered to receive competency restoration services in a timely manner. ${ }^{2}$ To assess the viewpoints of forensic directors and to understand what

\footnotetext{
vii It should be noted that the "fiscal year" varies between states. The states were told to code the fiscal year based on their state's definition.

viiiStates were asked to code this based on the 2016 FY. However, some states may have used the calendar year.
}

programs (if any) were being developed to provide mental health treatment to the defendants in a less intensive setting, new questions were developed. A total of 37 states returned completed surveys to the NRI.

\section{Analysis}

Data from the questionnaire were analyzed using version 24 of the Statistical Package for the Social Sciences (SPSS). Data collected from the tables were analyzed using Microsoft Excel.

Data on forensic statuses were analyzed in several ways. For each forensic status, as well as the total number of adult forensic patients, the national average and median were calculated for each year. Since responses across states can be impacted by different factors, percent change was used to examine individual state trends in regard to the state psychiatric hospital's forensic population. Percent change calculations were performed for three time periods: 1999-2005, 2005-2014, 1999 2014. To understand if changes were occurring across the nation, an "overall percent change" was computed. Finally, information on the number of patients admitted in 2016 was used to calculate admission rates. The 2016 admission rates were computed by dividing the number of forensic patients admitted to the state psychiatric hospitals in 2016 by the state's adult civilian population ${ }^{\text {ix }}$ and multiplying the result by 100,000 .

The final analysis examined the percentage of adult forensic patients among the state psychiatric hospital populations. In order to conduct this analysis, the NRI needed information on the number of adults (age $\geq 18$ ) present within each state psychiatric hospital on a given census day. The NRI collected this information from SAMHSA's Uniform Reporting System (URS). The URS database includes information on the number of patients over the age of 18 present in a state psychiatric hospital on a given census day for every year, which was used to determine the change in forensic population for each state between 2002 and 2014 .

\section{Missing data}

Some states were unable to provide the requested information in the stipulated time, and others were only able to provide partial data.

States with missing information could not be represented in the graphs depicting longitudinal trends. Throughout this paper, the trends of states with complete data for the time periods examined are only shown.

It should be noted that our presentation is entirely descriptive. We did not test hypotheses regarding

\footnotetext{
ix This refers to anyone who is $\geq 18$ years of age living in the state and not a member of the military.
} 
between-state differences or change from year to year. Doing so would have been difficult given the use of aggregate data and the small number of states and data points in this work.

\section{Results}

\section{Total adult forensic census}

The "total adult forensic" patient census includes all adult forensic inpatients (regardless of their forensic status/category) within a state psychiatric hospital on the designated census day. The national average of adult forensic inpatients between 1999 and 2014 has shown an increase during this period. While the average is helpful, it can be influenced by extremely high or extremely low values. However, the national median, which is unaffected by outlying values, shows the population trend to be fairly stable between 1999 and 2014. In essence, the differences between the national average and national median indicate that the outlying numbers impacted the trend line (Figure 1).

The results for the states that had complete data for 1999, 2002, 2004, 2005, 2006, 2010, 2011, and 2014 suggest that many of these states were experiencing a rise in state psychiatric hospital's forensic population. While for the most part the rise in the total adult forensic population was gradual, many of the states experienced a spike in state psychiatric hospital's total adult forensic population in 2011.

Each state is unique. Therefore, percent change calculations were performed for the 35 states that provided information on the total number of forensic patients present in their state psychiatric hospitals in 1999, 2005, and 2014 (Figure 2). Across all the 35 states, there was a $76 \%$ increase in the number of adult forensic patients present in their state psychiatric hospitals between 1999 and 2014. Across all the 35 states, the largest increase occurred between 2005 and 2014 (46\% increase across all the 35 states versus a $20 \%$ increase between 1999 and 2005). These results suggest that many of the states that had complete data for 1999 , 2005 , and 2014 experienced an increase in the number of adult forensic patients present in their state psychiatric hospitals between 1999 and 2014 .

The SPS does not capture data on the number of admissions to each state psychiatric hospital per year. While the "census day" data can be informative, it is limited by the fact that it only shows the number of individuals present on one day in a year. Admission rates were calculated using the 2016 data reported by the responding states. Of the 37 responding states, the number of adult forensic admissions in 2016 was reported by 32 states, of which 27 states had an admission rate of over 4 per 100,000 adult civilians (Figure 3). Overall, the median admission rate was 9.65 adult forensic patients per 100,000 adult civilians.

Census day information and admission rates are helpful for state comparisons. In addition, this information can be used to compare bed availability and allocation between forensic and civil patients in state hospitals. The number of beds available within state psychiatric hospitals obviously impacts admission rates, which, in turn, impact waitlists for beds. Information on the types of patients occupying these beds is important. This is especially true with regard to forensic patients, since some forensic patients may remain in state psychiatric hospitals for a long period of time. ${ }^{1-4}$

In order to calculate the utilization of beds, the analysis had to be restricted to examining data from 2002 through 2014 since the URS does not contain information prior to 2002 . Twenty-five states had complete data

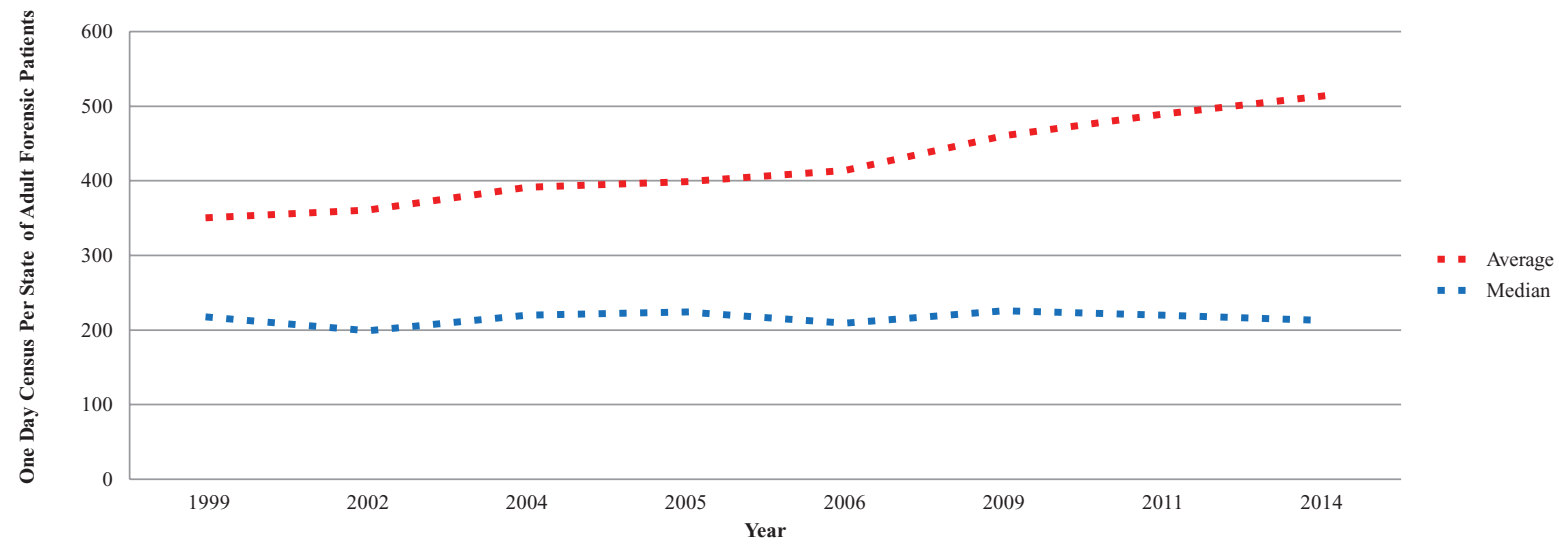

FIGURE 1. One-day census per state of adult forensic patients at state psychiatric hospitals, 1999-2014. Based on data from all 51 states.

Sources: 2017 NRI Inpatient Forensic Services Study; 1995-2015 State Mental Health Agency Profiling System. 


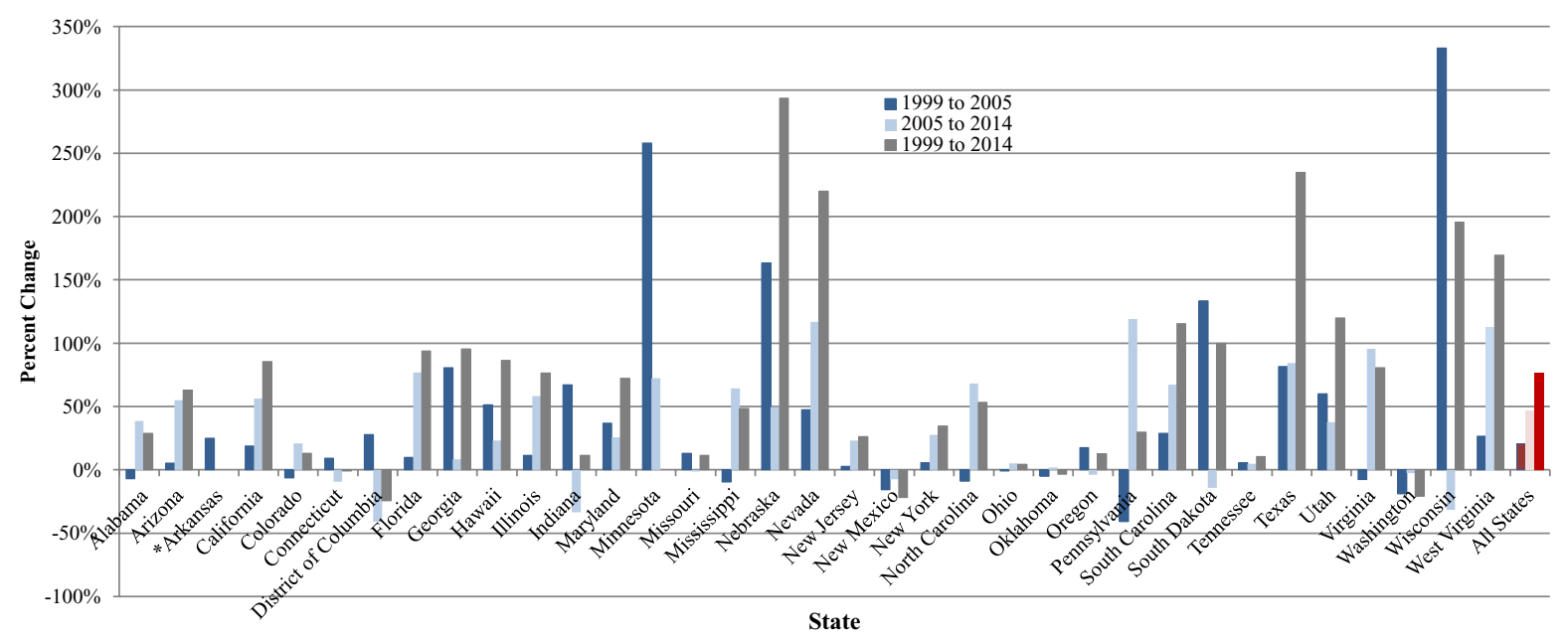

FIGURE 2. Percent change in inpatient forensic population. Based on data from 35 states for 1999, 2005, and 2014. Notes: Thirtyseven states had numerical data for these years. NH was removed since it reported having 0 forensic patient for 1999, 2005, and 2014. MA was removed. Their data is included in the data table for this graph, and was used to conduct the percent change for "All States." AR had a percent change of 1960\% for 2005-2014 and a percent change of 2475\% for 1999-2014. MN had a percent change of $517 \%$ for $1999-2014$.

Sources: 2017 NRI Inpatient Forensic Services Study; 1995-2015 State Mental Health Agency Profiling System.

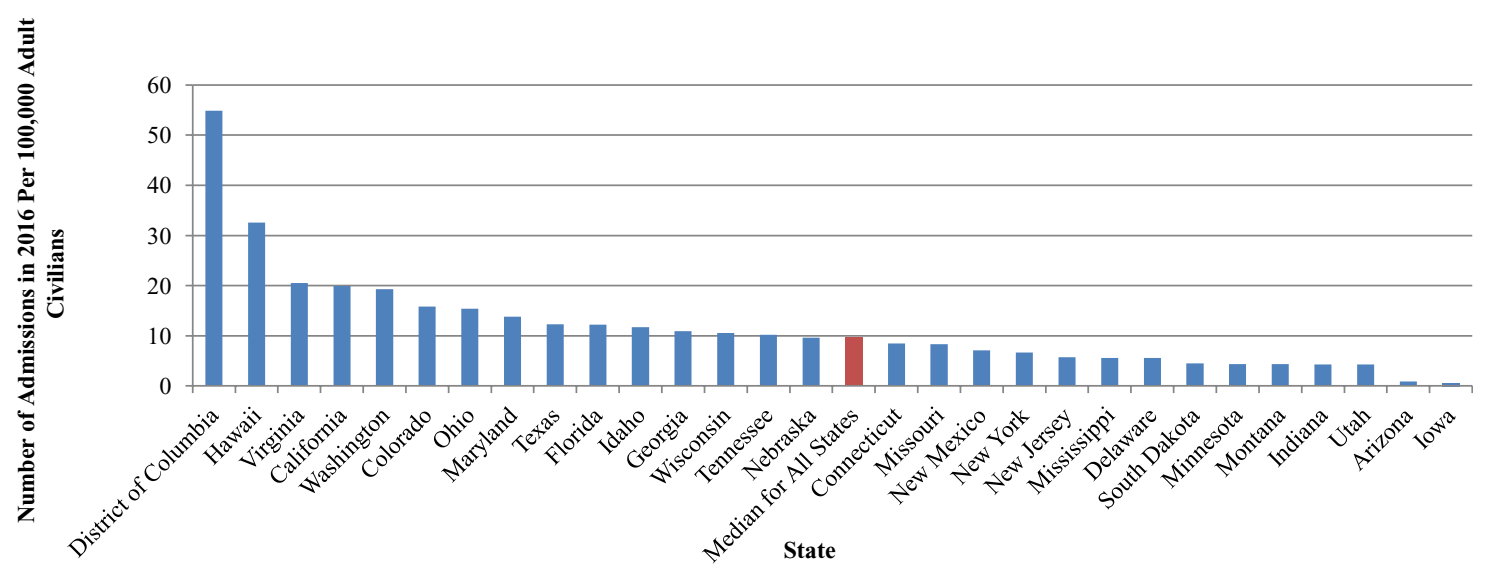

FIGURE 3. Rate of admission of adult forensic patients for inpatient services at state psychiatric hospitals in 2016. Based on data from 29 responding states. Notes: Thirty-two states reported admission data. NC, NH, and SC had admission rates of 0 per 100,000, so they were not included in the graph. IL, MA, MI, NV, and PA did not report, or did not have data available for 2016.

Source: 2017 NRI Inpatient Forensic Services Study.

for this time period. Changes in each state hospital's forensic composition are shown in Figure 4. Accordingly, only one state experienced a decrease in forensic population between 2002 and 2014. The remaining states experienced a rise in the number of forensic patients within their facilities.

Each analysis of the various adult forensic statuses indicates that there has been an increase in the number of adult forensic patients receiving inpatient services between 1999 and 2014. This rise appears to have resulted in a larger proportion of population in state psychiatric hospitals being forensic patients.
The results lead to further questions. Specifically, is a particular specific forensic status responsible for this increase? Or, is the rise in adult forensic population due to an increase in multiple forensic statuses receiving inpatient services? To answer these questions, a series of analyses were developed and are discussed below.

\section{Pre-trial evaluations}

The national average for the number of patients present for inpatient pre-trial evaluations on annual census days between 1999 and 2014 is higher than the national 


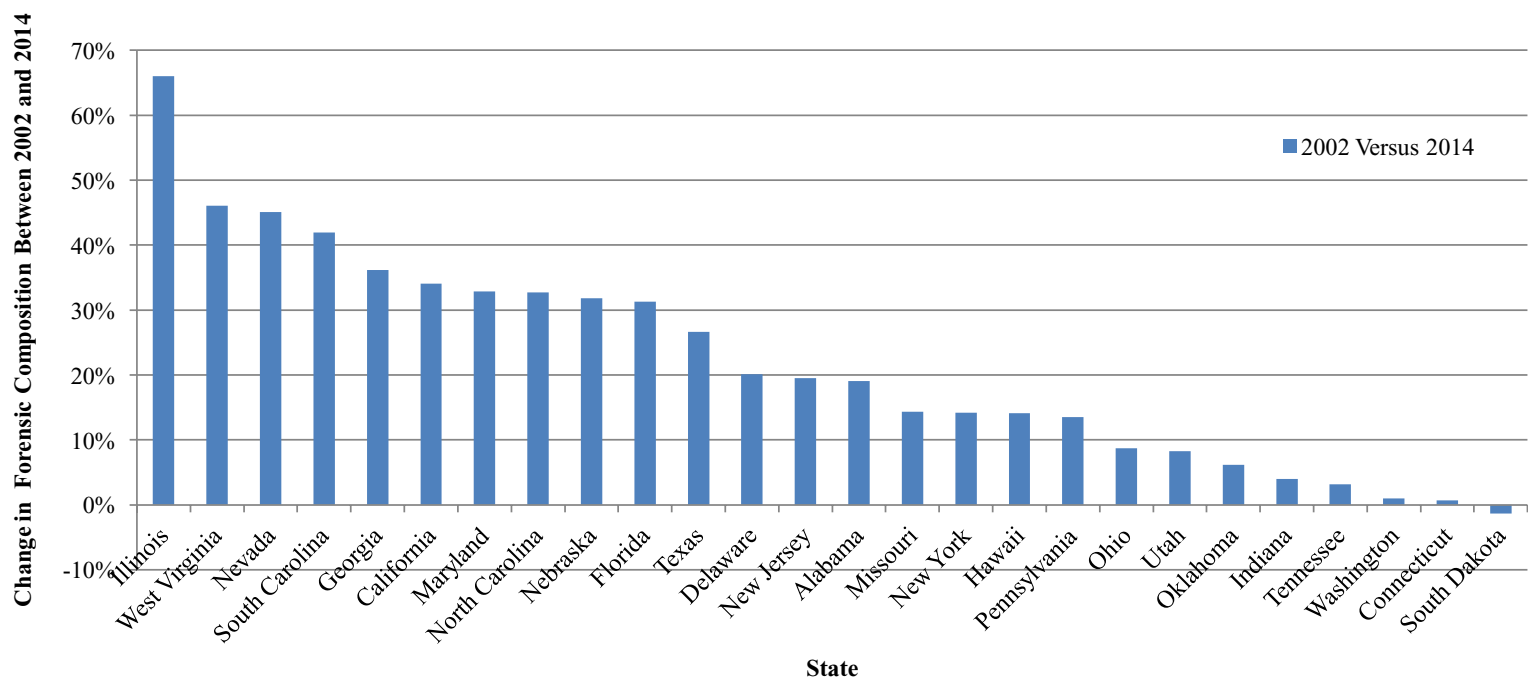

FIGURE 4. Change in the forensic composition of state psychiatric hospitals, 2002-2014. Based on data from 27 states for all 7 years. Notes: Twenty-eight states had data for 2002 and 2014. NH was removed from graph since it reported 0 forensic patient for either year. MA was removed from the graph due to a not-divisible-by-zero error. IL reported having 1213 forensic patients in 2014 , yet 513 patients were 18 or older. Data from 2013 was used for 2014. This made the number of adult state hospital residents 1232 for 2014. This caused a percent change of $66.0 \%$.

Sources: 2017 NRI Inpatient Forensic Services Study; Uniform Reporting System; 1995-2015 State Mental Health Agency Profiling System.

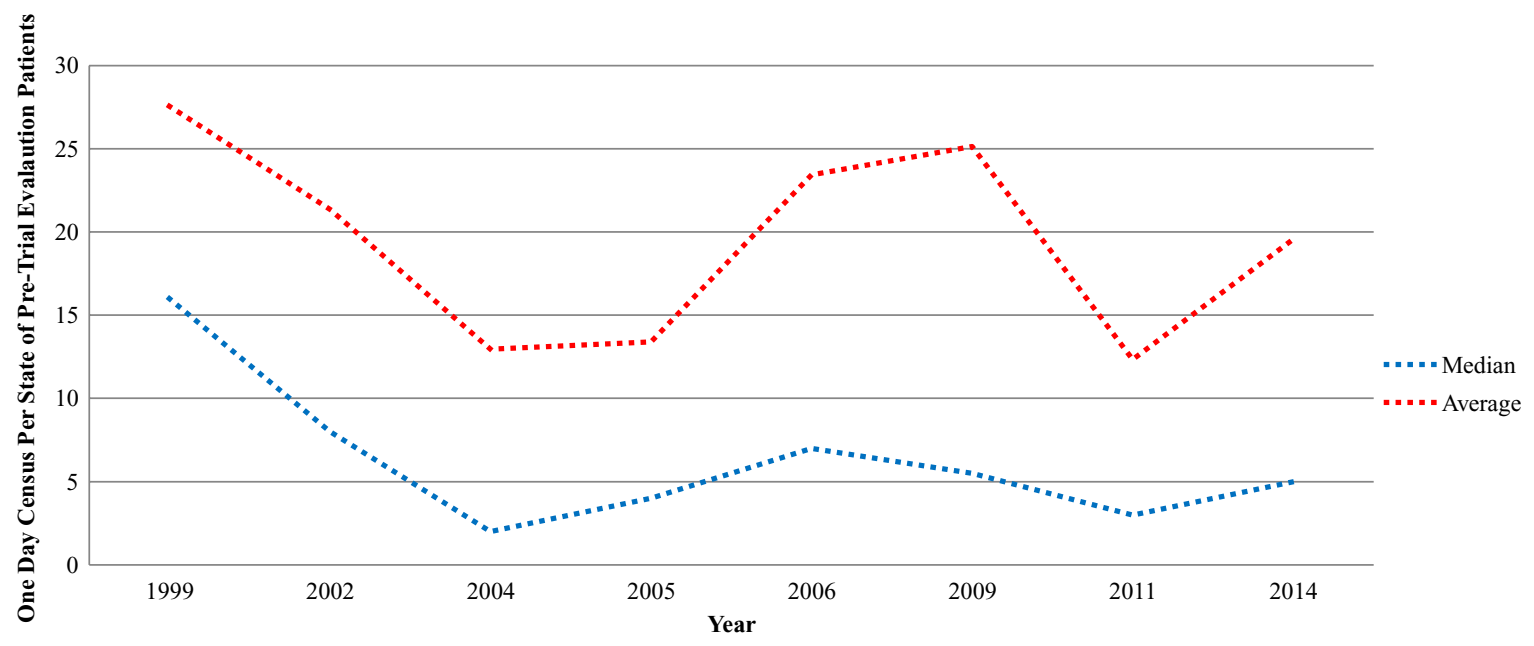

FIGURE 5. One-day census per state of patients present for pre-trial evaluation at state psychiatric hospitals, 1999-2014. Based on data from all 51 states. Notes: For Arkansas the number of patients present for pre-trial evaluation on the 2014 census day was removed from the average and median calculations for 2014.

Sources: 2017 NRI Inpatient Forensic Services Study; 1995-2015 State Mental Health Agency Profiling System.

median for this population (Figure 5). As with the total adult forensic status, the national average for this population is impacted by states with outlying data.

When changes within each state were examined, the percent change calculations suggest that among the 26 states with data for 1999, 2005, and 2014 (9 of which reported 0 forensic patients under pre-trial status), the rise in the number of patients present for pre-trial evaluation was a relatively new phenomenon. Between 2005 and 2014 these 17 states collectively saw an $84 \%$ rise in the number of forensic patients present on a given census day for pre-trial evaluation at state psychiatric hospitals (Figure 6).

Data from 15 of the reporting states included information on the number of patients admitted for pre-trial evaluations in 2016. Each of the 15 states had an admission rate 


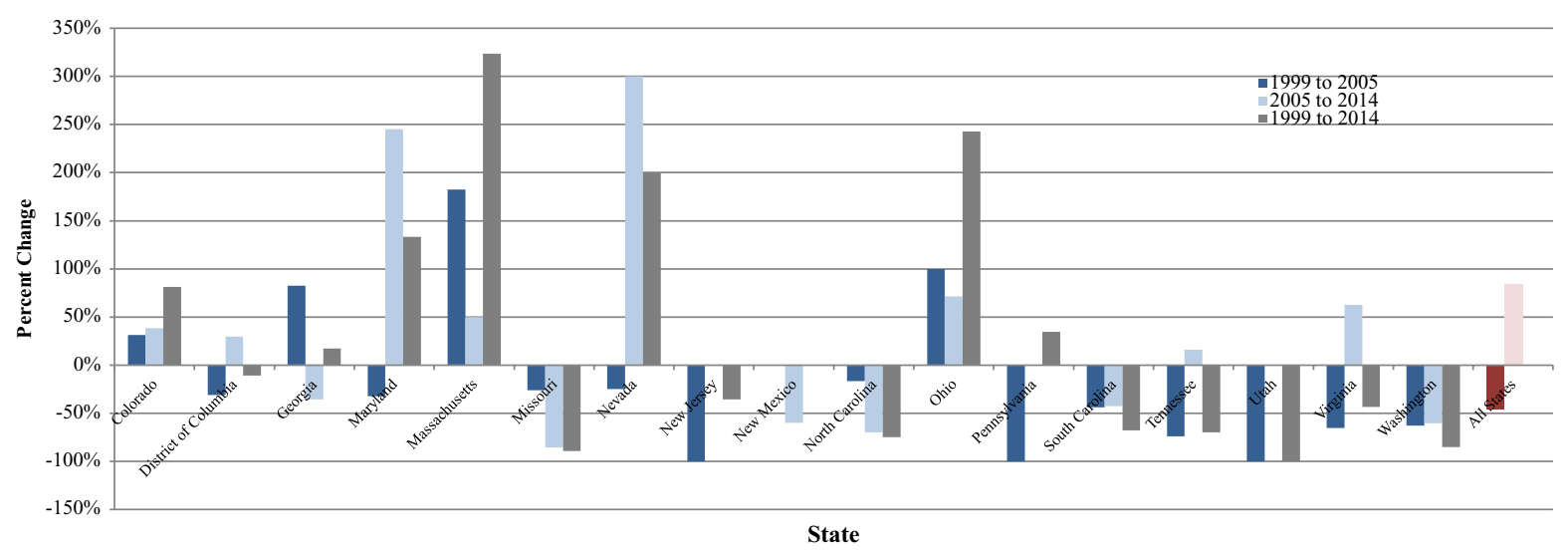

FIGURE 6. Percent change in inpatient population present for pre-trial evaluation, 1999-2014. Based on data from 17 states for 1999 , 2005, and 2014. Notes: Twenty-six states had data for these years. Several states (CA, CT, FL, IN, NE, NH, NY, SD, and TX ) were removed since they did not report having any patients present for pre-trial evaluation in 1999, 2005, and 2014. UT reported having 0 patient for pre-trial evaluation on the census days examined in 2005 and 2014.

Sources: 2017 NRI Inpatient Forensic Services Study; 1995-2015 State Mental Health Agency Profiling System.

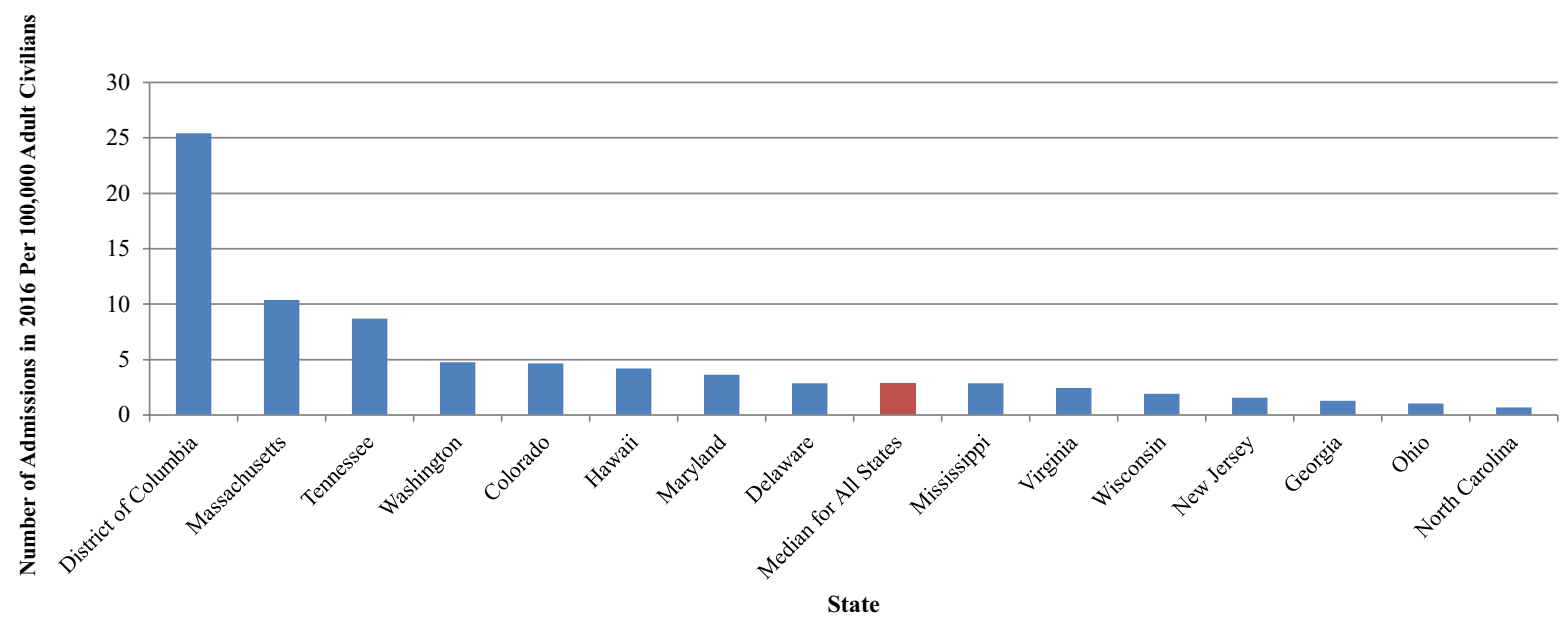

FIGURE 7. Rate of admission of patients to inpatient services for pre-trial evaluation at state psychiatric hospitals in 2016. Based on data from 15 responding states. Notes: Thirty-four states reported admissions data for 2016. AZ, CA, CT, FL, ID, IL, IN, MN, MT, NE, NH, NY, SD, TX, and UT were removed from the graph since they had admission rates of 0 per 100,000. IA, MO, NM, and SC had admission rates of 0.2 per 100,000. MI, NV, and PA did not report or did not have data available for 2016 . Therefore, the data for these states are missing. Source: 2017 NRI Inpatient Forensic Services Study.

$\geq 1$ per 100,000 adult civilians. Eleven had an admission rate between 1 and 5 per 100,000 adult civilians. Three states had admission rates that were relatively high (Figure 7).

\section{IST restoration services}

The data obtained for this study suggest that there has been a rise in the number of IST patients receiving competency restoration services during our observation period. The national average and median both showed an increase between 2005 and 2014 (Figure 8).

The 27 states with complete data for 1999, 2005, and 2014 collectively show a $72 \%$ increase in IST patients present on the census day (Figure 9).
Based on the IST admission data for 22 states, the rates of patient admission for IST restoration were higher than that for pre-trial evaluations. The admission rate of IST patients in 22 states (out of the 34 states that responded with complete data) was $>3$ per 100,000 adult civilians (See Figure 10).

\section{Discussion}

The results presented here show a rise in the number of adult forensic patients present in state psychiatric hospitals on a given census day between 1999 and 2014. Additionally, based on the data obtained from the SPS, 


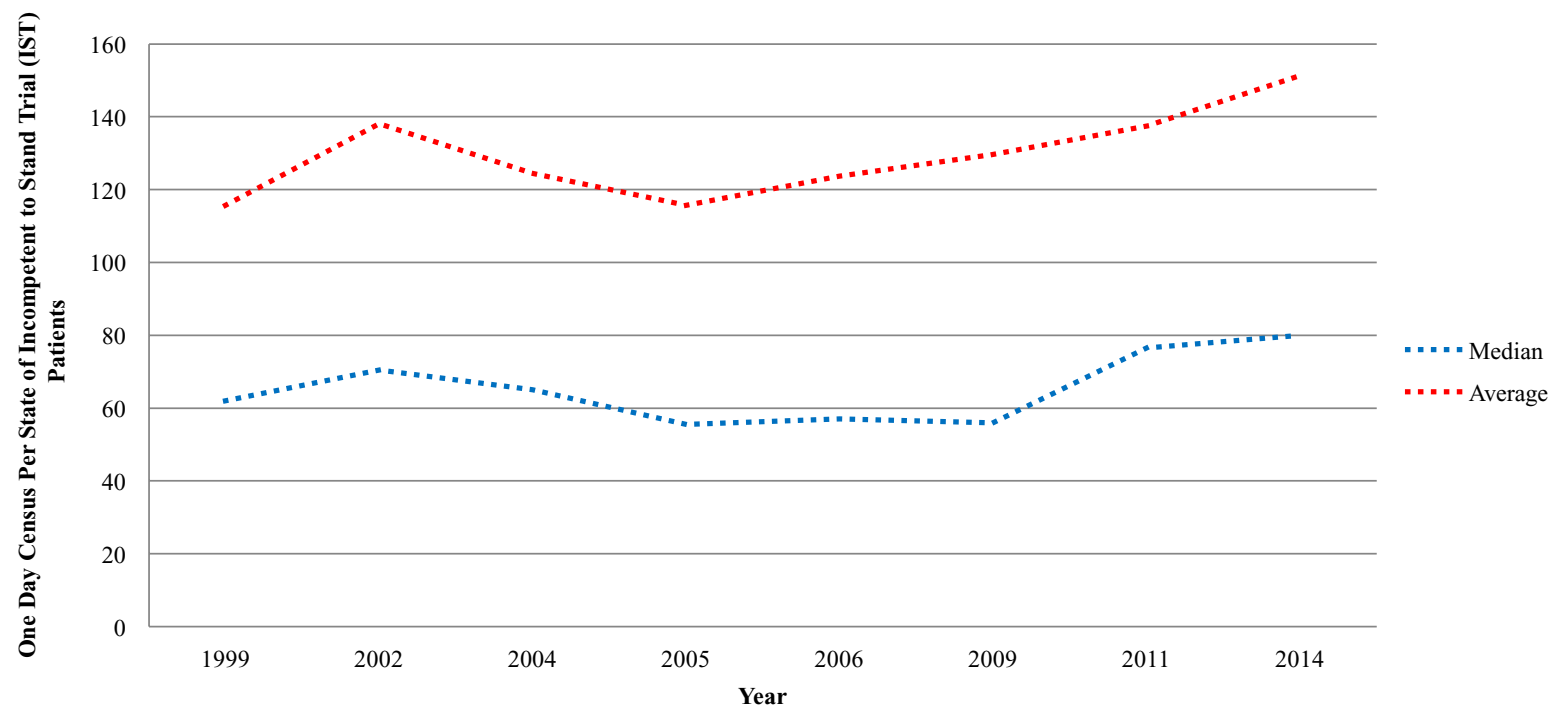

FIGURE 8. One-day census per state of IST patients present at state psychiatric hospitals, 1999-2014. Based on data from all 51 states.

Sources: 2017 NRI Inpatient Forensic Services Study; 1995-2015 State Mental Health Agency Profiling System.

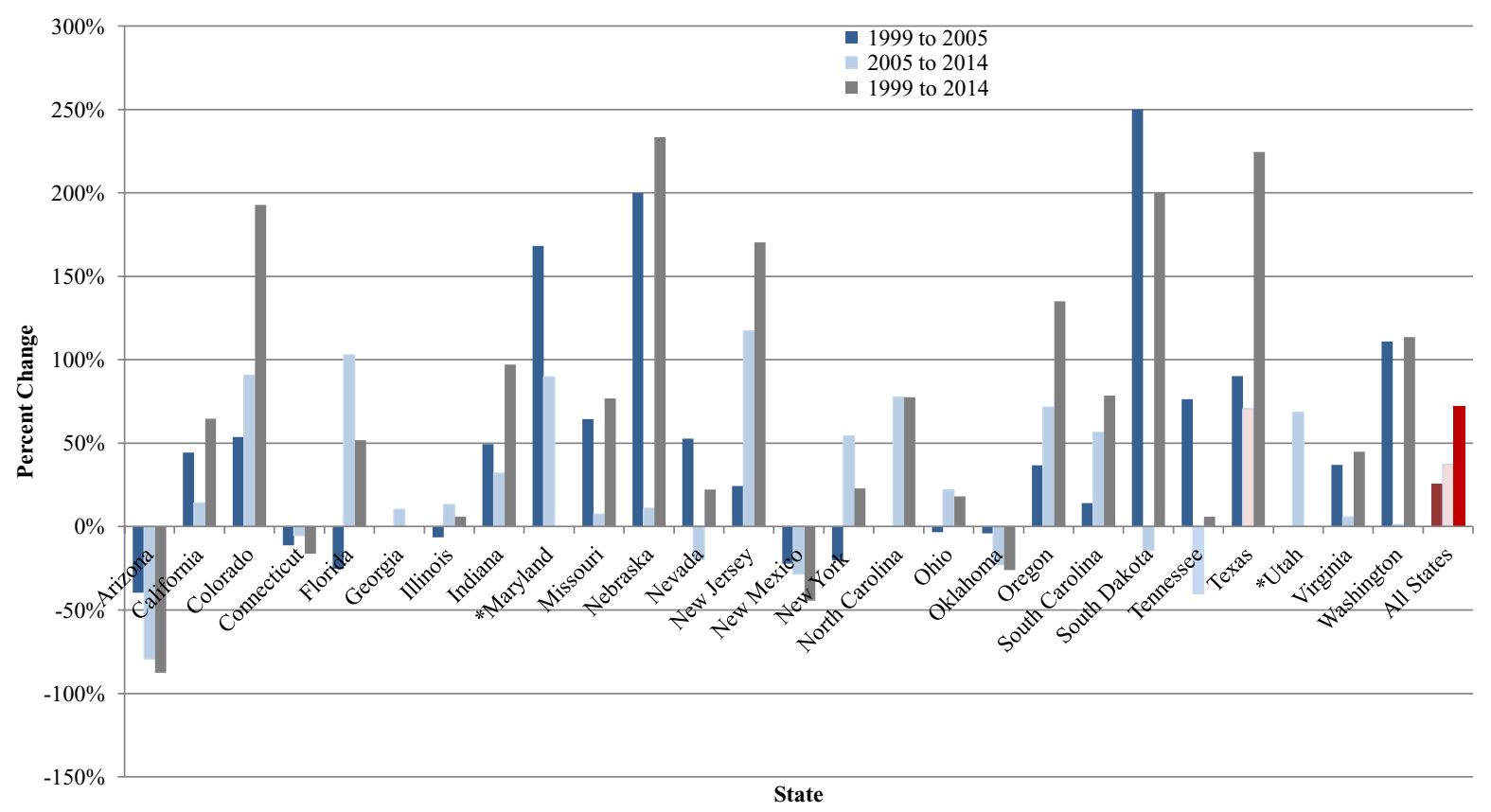

FIGURE 9. Percent change in inpatient IST population, 1999-2014. Based on data from 26 states for 1999, 2005, and 2014. Notes: Twenty-seven states had data. NH was removed since it had 0 IST patients for 1999, 2005, and 2014. GA had a percent change of $302 \%$ for $1999-2005$ and $344 \%$ for 1999-2014. MD had a percent change of 409\% for 1999-2014. UT had a percent change of $629 \%$ for $1999-2005$ and $1129 \%$ for $1999-2014$.

Sources: 2017 NRI Inpatient Forensic Services Study; 1995-2015 State Mental Health Agency Profiling System.

this rise was apparent in a majority of states. Furthermore, when each of the forensic statuses was examined, the data appear to suggest that IST patients - those who might spend a longer period of time in hospitals in an attempt to restore competency — were primarily responsible for the rise in the adult forensic population. Since many of the state psychiatric hospitals are facing pressure to admit civil as well as forensic patients, such information is important. This was occurring at a time when the number of inpatient beds in all sectors has greatly reduced, leading 


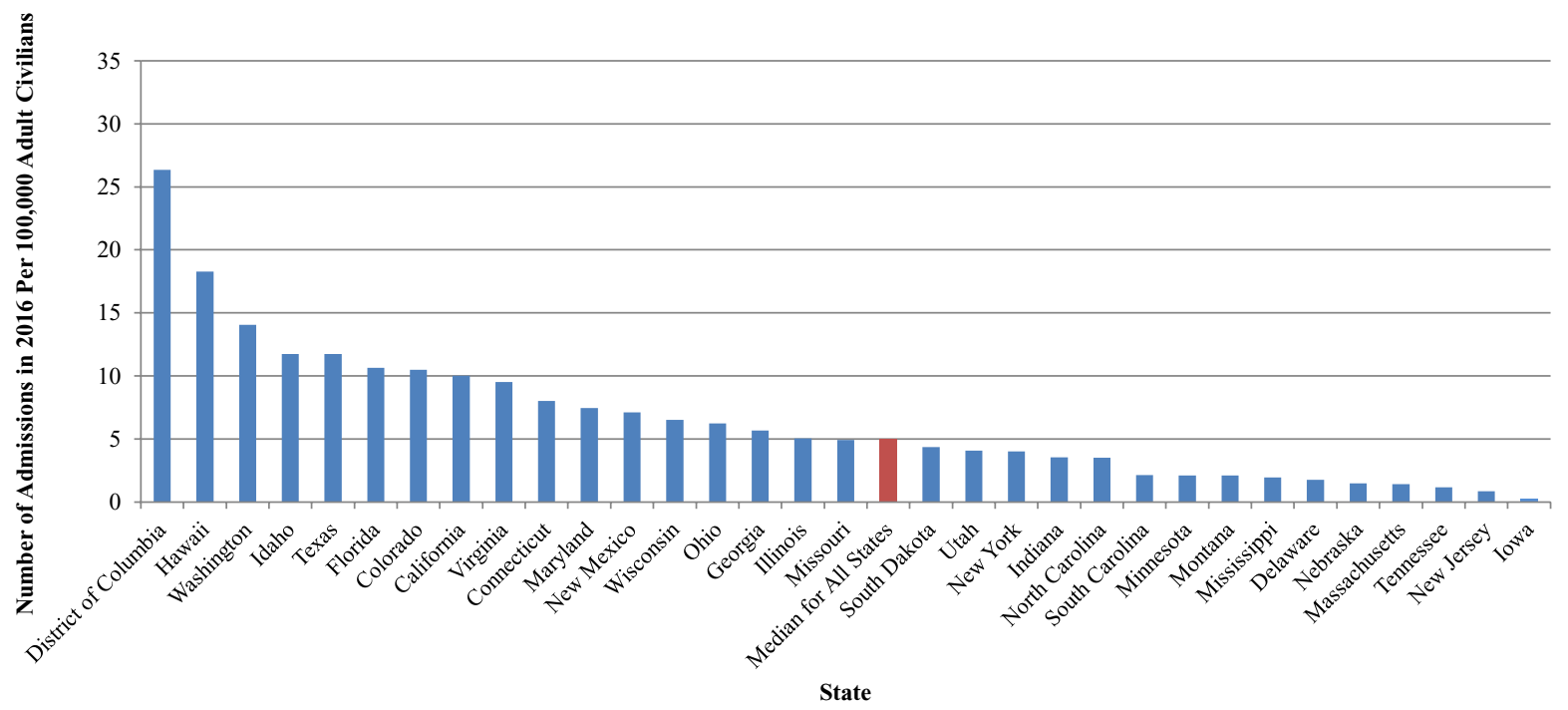

FIGURE 10. Rate of admission of IST patients for inpatient services at state psychiatric hospitals in 2016 . Based on data from 32 responding states. Notes: Thirty-four states had admission data for 2016. Two states ( $\mathrm{NH}$ and AZ) were not included in the graph since $\mathrm{NH}$ had an admission rate of 0 per 100,000 and AZ, 0.2 per 100,000. MI, NV, and PA did not report or did not have data available for 2016. These states were not included in the graph.

Sources: 2017 NRI Inpatient Forensic Services Study.

many states to develop waitlists. ${ }^{1-5,8,9}$ With regard to competency restoration, IST defendants may be waitlisted anywhere from several days to a year or more. ${ }^{1-5}$ Many state psychiatric hospitals have faced legal action as a result of their lengthy wait times; ${ }^{1-5}$ indeed, 20 of the 37 responding states $(54 \%)$ indicated that they had been (or were currently being) threatened with or actually held in contempt of court for failing to reduce wait times. Many of these states reported implementing a variety of strategies to reduce wait times for competency restoration services to IST patients. The commonly reported strategies include, but are not limited to, implementing outpatient competency restoration programs, creating and/or implementing jail-based competency restoration programs, creating additional state psychiatric hospital beds, hiring more forensic state psychiatric hospital workers, improving their admission processes (e.g., making it centralized and/or developing new prioritization standards), and increasing collaboration between mental health and criminal justice agencies.

Forensic patients are an important but often overlooked population within state psychiatric hospitals, yet state psychiatric hospitals spend approximately one-third of their budgets on forensic patients. As the number of forensic patients has increased over the years, the amount being spent on them has similarly increased. ${ }^{9}$ Meanwhile, the proportion of inpatient budget spent on civil patients has decreased (Figure 11). It should be noted that while the amount being allocated to forensic patients may be impacted by how much of the inpatient budget can be spent on civil patients (and vice versa), it can also be impacted by additional factors. Specifically, the inpatient budget spent on civil patients is affected by the fact that more civil patients are being served in outpatient and other community-based settings. ${ }^{9}$ This, in turn, means that fewer civil patients are being admitted to inpatient settings. In essence, the increasing preponderance of forensic patients in state psychiatric hospitals suggests a shift in the functioning of such facilities as these become an adjunct to the criminal justice system a direction that was never envisioned as part of the mission of state mental health agencies.

\section{Limitations}

Our study has several limitations. As noted in the Methodology section, some states were unable to respond to the survey and so the data pulled from existing data sources could not be verified. The fact that such data were used in the analyses could have impacted the results.

A second limitation is that the data collection methods that state psychiatric hospitals were required to follow may have changed over time. This could lead to significant differences within and between states, which makes comparisons more complicated. A third limitation of the data set is that it was difficult to determine if the states may have duplicated cases with more than one status (e.g., IST and sex offender). Consequently, the data used for this study might contain duplicated cases depending on whether each state psychiatric hospital coded forensic patients as belonging to multiple forensic statuses. This limitation can impact the interpretations of state data. 


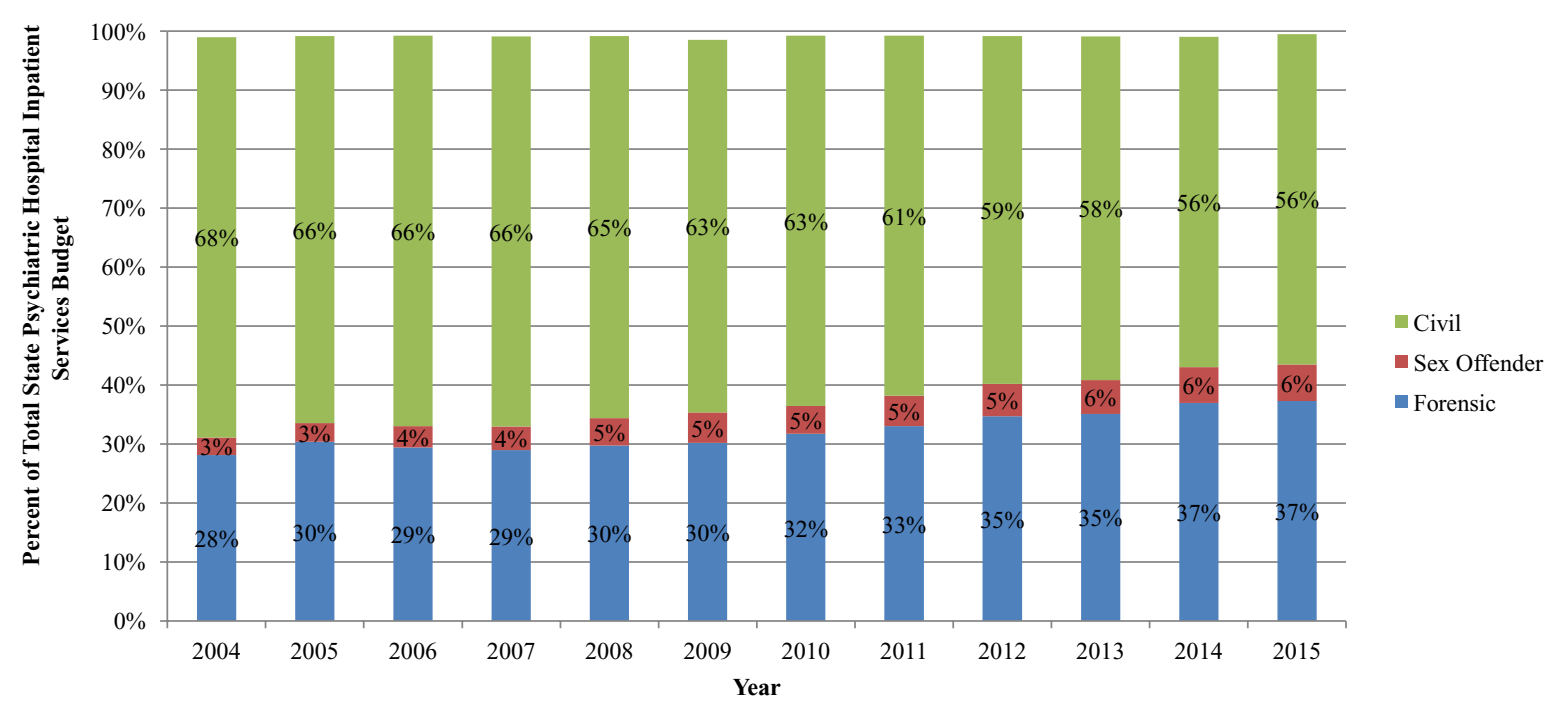

FIGURE 11. US state psychiatric hospital inpatient services budget spending, 2004-2015. Based on data from all 51 states. Source: State Revenues and Expenditure Study.

States that did not duplicate information may have prioritized a particular forensic status over others for forensic patients with multiple statuses. Without knowing how each state coded patients with multiple statuses, comparisons between states need to be done with caution.

Another limitation is that only criminal defendants are "at risk" for forensic admissions, and a better denominator for adjusting these data would be the number of adult criminal court arraignments in each state. However, obtaining such information at the level required would have been difficult and well beyond this study's scope and available resources.

Lastly, one-day census data were used as a proxy for the number of adult beds to compute the total adult forensic composition of state psychiatric hospitals. The reader should keep these limitations in mind when interpreting the results of this study.

\section{Conclusion}

The findings of this study support the perceptions of many state officials who are concerned that the forensic population is, indeed, increasing ${ }^{1-5}$ and that the phenomenon is not unique to just a couple of states. The results presented here demonstrate that there was a rise in the number of adult forensic patients nationally, specifically IST patients, in state psychiatric hospitals between 1999 and 2014. This trend was not experienced by every state, since each state varies with respect to how it manages competency evaluation and restoration process.

This study described the trends in the number of defendants being admitted to state psychiatric hospitals. Future studies need to do a more in-depth examination of the types and effectiveness of strategies undertaken by various states to reduce forensic admissions. Such information could help states determine what methods might be most applicable to the management of forensic population, thereby avoiding negative consequences (e.g., held in contempt for lengthy wait times). These data could provide a useful baseline for future analyses.

The study raises several questions. Why is this increase occurring now? Who are these forensic patients? Are they new to the mental health system, or have they previously received services as "civil patients" and have newly encountered the criminal justice system? Have community-based services had an effect? In an era when many jurisdictions are developing diversion programs, how is it that so many persons displaying symptoms of mental health issues are still appearing in criminal courts? Keeping in mind that these referrals might have an effect on the judiciary, what are judges' views on this increase? Are forensic referrals really about the capacity to stand trial, or are these, in reality, a coping strategy used by judges to ensure access to mental health services for defendants who appear to need them? Indeed, ordering a CST evaluation may be a simple, temporary — albeit inappropriate - solution to such problems.

Mental health services researchers have paid relatively little attention to this segment of public mental health systems and their clientele. Given an increasing presence of forensic patients and its growing burden on restoration resources across multiple states, the subject deserves a greater focus of attention.

\section{Acknowledgements}

The authors gratefully acknowledge the expertise and technical review provided by the following national experts on forensic mental health services: Debra A. Pinals, M.D., W. Lawrence Fitch, J.D., and Katherine 
Warburton, D.O. Without their guidance, a study of this magnitude could not have been completed. We also extend our appreciation to the State Forensic Directors and other staff collaborators who spent many hours compiling and reviewing data for this study. The authors assume all responsibility for the scientific content of the paper.

\section{Funding}

This work was developed under Task 2.2 of NASMHPD's Technical Assistance Coalition contract/task order, HHSS283201200021I/HHS28342003T, and funded by the Center for Mental Health Services/SAMHSA of the Department of Health and Human Services through the NASMHPD.

\section{Disclosures}

The authors (Amanda Wik and Vera Hollen) are employees of the NRI, and William Fisher is an NRI paid consultant. The authors maintained full independent control over study design, data collection and analysis, and the contents of written reports.

\section{Ethical Considerations}

The authors report no ethical considerations to disclose in regard to this study.

\section{REFERENCES}

1. Colorado Department of Human Services. Needs analysis: Current status, strategic positioning, and future planning. https://www.nriinc.org/media/1109/2015-colorado-department-of-human-servicebehavioral-health-needs-analysis-nri.pdf. Published April 2015. Accessed April 2019.
2. Fitch, LW. Assessment \#3: Forensic mental health services in the United States: 2014. https://www.nasmhpd.org/sites/default/files/ Assessment\%203\%20\%20Updated\%20Forensic\%20Mental\% 20Health\%20Services.pdf. Published September 2014. Updated October 2014. Accessed April 2019.

3. Nobles, J, Randall, J. Evaluation report: Mental health services in county jails. http://www.auditor.leg.state.mn.us/ped/pedrep/ mhjails.pdf. Published March 2016. Accessed April 2019.

4. PCG. Initial findings report: Washington mental health system assessment. http://www.ofm.wa.gov/reports/

MentalHealthSystemAssessmentInitialFindings.pdf. Published November 2016. Accessed April 2019.

5. Washington State Department of Social and Health Services. Cassie Cordell Trueblood, et al., v. Washington State Department of Social and Health Services, et al. Case No. C14-1178 MJP monthly report to the court appointed monitor. https://www.dshs.wa.gov/sites/ default/files/BHSIA/FMHS/Trueblood/2017Trueblood/ Trueblood-Report-2017-07.pdf. Published 2017. Accessed April 2019.

6. Miller, RD. Hospitalization of criminal defendants for evaluation of competence to stand trial or for restoration of competence: Clinical and legal issues. Behav Sci Law. 2003; 21 : 369-391.

7. Fisher, WH, Geller, J L, Pandiani, JA. The changing role of the state psychiatric hospital. Health Affairs. 2009; 28(3): 676-684. doi: 10.1377/hlthaff.28.3.676.

8. Parks, J, Radke, A. The vital role of state psychiatric hospitals. https//nasmhpd.org /content/vital-role-state-psychiatric-hospitalsjuly-2014-0. Published July 2014. Accessed April 2019.

9. Lutterman, T, Shaw, R, Fisher, W, Manderscheid, R. Trend in psychiatric inpatient capacity, United States and each state, 1970 to 2014. https://www.nri-inc.org/media/1319/tac-paper-10psychiatric-inpatient-capacity-final-09-05-2017.pdf. Published August 2017. Accessed April 2019.

10. Legislative Budget Board Staff. Texas state government effectiveness and efficiency report: Selected issues and recommendations. https://www.lbb.state.tx.us/Documents/ Publications/GEER/Government\%20Effectiveness\%20and\% 20Efficiency\%20Report\%202012.pdf. Published January 2013. Accessed April 2019. 